\title{
Besides and Beyond Histopathology; for Adjuvant Treatment in Early Tongue Cancer
}

\begin{abstract}
Oral tongue squamous cell carcinomas differ significantly from that of other subsites of oral cavity in relation to clinical behavior. They are more aggressive and have a poorer prognosis. The treatment of choice of early (stage I and II) tongue cancers is surgery. The need for adjuvant treatment is decided on the basis of the histopathology report of the surgical specimen. High-risk patients (positive surgical margins, perineural invasion, lymphovascular spread, lymph node metastasis, and extracapsular extension) receive adjuvant treatment while others are observed. Unfortunately, in the apparently low-risk patients who are observed, there is a high rate of locoregional failure. There are certain histopathology parameters though not routinely validated may be of prognostic significance in this subset of patients. In this review, we have highlighted the importance of the routinely validated and the nonvalidated histopathology parameters and their proper assessment in the decision-making for adjuvant treatment of patients with early tongue cancers.
\end{abstract}

Keywords: Adjuvant therapy in tongue cancers, early squamous cell carcinoma tongue, indications for radiotherapy in tongue cancers, molecular markers in tongue cancers

\section{Introduction}

Oral tongue cancers are distinct epidemiologically and biologically from cancers of other subsites of the oral cavity. They are more common in females, patients aged below 40 years, and nonsmokers. ${ }^{[1-4]}$ Rusthoven retrospectively compared survival in patients with early squamous cell carcinoma (SCC) of the oral tongue (cT1-2 N0 M0) with that in patients with SCC in other oral cavity subsites using the surveillance, epidemiology, and end results' database. ${ }^{[5]}$ Six thousands seven hundred and ninety-one patients were identified of whom $40 \%$ had oral tongue cancers and $60 \%$ had cancers of other subsites of the oral cavity. The 5-year overall survival (OS) and cause-specific survival (CSS) rates were $60.9 \%$ and $83.5 \%$, respectively, for patients with oral tongue SCC versus $64.7 \%$ and $94.1 \%$, respectively, for patients with SCC of other oral cavity subsites $(P<0.0001$ for both OS and CSS). He concluded that the prognosis of oral tongue cancer varies considerably as compared to cancer of other subsites of the oral cavity.

Treatment of stage I and II oral tongue cancers is primarily surgery. Surgery usually

This is an open access journal, and articles are distributed under the terms of the Creative Commons Attribution-Non Commercial-ShareAlike 4.0 License, which allows others to remix, tweak, and build upon the work non-commercially, as long as appropriate credit is given and the new creations are licensed under the identical terms.

For reprints contact: reprints@medknow.com comprises of wide excision of the lesion with level I-IV selective neck dissection. In the busy oncological clinics, the decision for adjuvant therapy is based on certain fixed postoperative histopathological parameters. Patients with poorly differentiated tumors, close or positive margins, perineural invasion (PNI), lymphovascular spread, deep infiltrative tumors or nodal metastasis with or without extracapsular extension receive adjuvant therapy. The rest without any of these adverse features are kept under observation. However, in our clinical practice, a significant number of the "apparently low-risk patients" develop early locoregional recurrence and their prognosis is dismal. We searched the literature and found similar results in different retrospective case series [Table 1]..$^{[6-10]}$

This scenario raises a few pertinent questions.

Are we missing something in these patients?

Would adjuvant therapy have benefitted them?

Can histopathology report give us an answer?

Routine histopathology comprises assessment of certain parameters such as

How to cite this article: Chakrabarti S, Ghosh S,
Qayyumi BN, Malik A, Nair D, Nair S, et al. Besides
and beyond histopathology; for adjuvant treatment
in early tongue cancer. Indian J Med Paediatr Oncol
2018;39:355-62.
Qayyumi BN, Malik A, Nair D, Nair S, et al. Besides and beyond histopathology; for adjuvant treatment 2018;39:355-62.

\section{Swagnik \\ Chakrabarti, Shreshtha Ghosh ${ }^{1}$, Burhanuddin N Qayyumi', Akshat Malik, Deepa Nair, Sudhir Nair, Pankaj Chaturvedi, JP Agrawal'}

Department of Head and Neck Surgical Oncology and ${ }^{2}$ Radiation Oncology, Tata Memorial Hospital, Parel, ${ }^{1}$ Department of Pathology, MGM Medical College, Mumbai, Maharashtra, India

Address for correspondence: Dr. JP Agrawal, Department of Radiation Oncology, Tata Memorial Hospital, Dr E. Borges Road, Parel, Mumbai - 400 012, Maharashtra, India.

E-mail:jpathm@hotmail.com

Access this article online

Website: www.ijmpo.org

DOI: 10.4103/ijmpo.ijmpo_204_16 Quick Response Code:

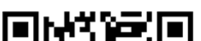




\begin{tabular}{|c|c|c|c|}
\hline Author & Year of publication & Study design & Results \\
\hline Han et al. ${ }^{[6]}$ & 2007 & Retrospective study $(n=125)$ & 5 years OS $62.59 \%$ \\
\hline An et al..$^{[7]}$ & 2008 & Retrospective study $(n=63)$ & $\begin{array}{l}5 \text { years OS rate } 97.1 \% \text { in Stage I and } 76.2 \% \text { in stage II, and } 5 \text {-years } \\
\text { disease-free survival rate } 76.7 \% \text { in stage I and } 43.5 \% \text { in stage II }\end{array}$ \\
\hline Sopka et al..$^{[8]}$ & 2013 & Retrospective study $(n=126)$ & 3- and 5-year actuarial local control $77 \%$ and $73 \%$, respectively \\
\hline Mantsopoulos et al. ${ }^{[9]}$ & 2014 & Retrospective study $(n=263)$ & $\begin{array}{l}\text { The } 5 \text {-year OS } 56.9 \% \text {, disease-specific survival rate } 75.2 \% \text { and } \\
\text { local control was } 86.3 \%\end{array}$ \\
\hline Yanamoto et al..$^{[10]}$ & 2013 & Retrospective study $(n=58)$ & $\begin{array}{l}\text { The } 5 \text {-year disease specific and recurrence free survival } 89.5 \% \\
\text { and } 73.3 \% \text {, respectively }\end{array}$ \\
\hline
\end{tabular}

OS - Overall survival

margins, tumor thickness, grade of differentiation, PNI, vascular invasion, and nodal status. However, beyond the usual known factors, quite a few histopathological factors come into our minds that are not routinely validated. Some of these are cost-effective and simple while others are costly and time-consuming.

This article is a review of the histopathological parameters (both validated and nonvalidated) that are of importance in deciding upon adjuvant therapy.

\section{Validated Parameters}

Assessed routinely, these factors are of prime importance in postoperative adjuvant therapy decision-making. However, the correct pathological interpretation of these at times can be tricky owing to the complex anatomy of the surgical specimen.

\section{Margins}

Time and again, the role of surgical margin has been emphasized in literature. Local tumor control is best achieved by complete surgical excision with "adequate" resection margins. Although the concept of positive margin is fairly straightforward (surgical "cut through" the tumor with tumor cells seen at the resected margins), considerable confusion surrounds the definition of "close" margins. Most studies that specifically define margin distance use a definition of $\geq 5 \mathrm{~mm}$ to define margin adequacy. Chen et al. ${ }^{[11]}$ reported on 270 consecutive operated patients of oral cavity, oropharynx, hypopharynx, and larynx, using a defined $5 \mathrm{~mm}$ margin standard. Locoregional recurrence and 5-year disease-free survival (DFS) rates were 55\% and $7 \%$ versus $17 \%$ and $39 \%$, for patients with inadequate versus adequate margins, respectively. Similarly, Loree and Strong ${ }^{[12]}$ reported the outcome for 398 consecutive patients with oral cancer, using a defined $5 \mathrm{~mm}$ standard for margins. Locoregional recurrence and 5-year OS rates were $30 \%$ and $52 \%$ versus $18 \%$ and $60 \%$ for patients with inadequate versus adequate margins, respectively.

Contrary to the mucosal margins which are visible, assessment of depth of resection requires intraoperative palpation of the specimen. Woolgar et $a l^{[13]}$ in a review of 301 patients with oral and oropharyngeal cancers operated with curative intent found $87 \%$ of the inadequate margins $(61 / 70)$ were at the depth as opposed to only $16 \%$ at the mucosal margins (11/70). Less than $2 \%$ of 301 resections had inadequate margins solely on the basis of mucosal margins.

How to measure the surgical margin?

The resected surgical specimen should initially be grossly examined by the surgeon to assess for the mucosal and the deep margins. This includes apart from visual examination, thorough palpation of the specimen to identify any induration along or close to the resected margins. This is especially essential at the depth where the tumor is usually infiltrative. The closest gross margin should be marked and sent to the pathologist for assessment. Sections should be taken from the tumor invasive front to the nearest surgical resection edge in a "perpendicular direction" and measured in millimeters. This is in distinction to parallel, en face margins, which assess greater surface area, but do not allow for the measurement of margin distance.

The treatment of patients with positive or close resection margin is reexcision or adjuvant therapy. Reresection is technically difficult in tongue cancers as opposed to bone revision due to two reasons. First, the exact site of close margin is difficult to assess due lack of definable landmarks. Second, tongue being a muscular structure, the remnant part retracts deep in the musculature after initial resection. Hence, in most cases, inadequate margins would need to be supplemented with adjuvant treatment, based on the comparative analysis of two randomized clinical trials. ${ }^{[14]}$

Most guidelines including the National Comprehensive Cancer Network (NCCN) and the European Society for Medical Oncology guidelines advocate adjuvant chemoradiotherapy for positive margins and not for close margins. ${ }^{[15,16]}$ We also advocate similar treatment protocol. However, a close margin should be analyzed meticulously for any foci of margin positivity before subjecting the patient to less aggressive adjuvant treatment (radiotherapy [RT] only).

\section{Tumor Thickness}

Tumor thickness denotes the maximum perpendicular dimension of the tumor measured from the surface 
of the lesion to the deepest point, whereas depth of invasion represents the extension of the tumor beneath the epithelial surface. Tumor thickness has been shown as an independent risk factor for locoregional recurrence in many studies. In a cohort of 85 patients with oral tongue carcinoma, Yuen et al. ${ }^{[17]}$ found tumor thickness to be a significant predictor for nodal metastasis, local recurrence, and DFS. In multivariate analysis, tumor thickness was the only predictor for nodal metastasis. Woolgar $^{[18]}$ demonstrated that the mean reconstructed thickness for tumors with pathologically positive nodes was $19 \mathrm{~mm}$ as compared to $10 \mathrm{~mm}$ for pathologically negative nodes. Fukano et al.$^{[19]}$ showed in 34 patients that the incidence of cervical metastasis increased from 5.9\% for tongue carcinomas $<5 \mathrm{~mm}$ thick to $64.7 \%$ for tongue carcinomas $>5 \mathrm{~mm}$ thick. Brown et al. ${ }^{[20]}$ noted that $38 \%$ of patients with tumor thickness $<3 \mathrm{~mm}$ developed regional disease, compared with $41 \%$ of patients with tumor thickness of $3 \mathrm{~mm}$ to $7 \mathrm{~mm}$ and with $55 \%$ of patients with tumor thickness $>7 \mathrm{~mm}$. He also showed that increasing tumor thickness is associated with greater PNI. Fakih et al. ${ }^{[21]}$ noted that in $\mathrm{T} 1$ and $\mathrm{T} 2 \mathrm{SCC}$ of the oral tongue, a thickness $>4 \mathrm{~mm}$ is associated with a greater risk of neck relapse. In another recent study from our own institution, Thiagarajan $\mathrm{S}$ et al ${ }^{[22]}$ found a tumor thickness cutoff of $11 \mathrm{~mm}$ significantly affected the OS. In a retrospective analysis of 164 patients of stage I and II oral tongue SCC who underwent partial glossectomy with ipsilateral neck dissection without adjuvant RT, Ganly et al. ${ }^{[23]}$ found regional recurrence rate was $5.7 \%$ for tumors $<4 \mathrm{~mm}$ and $24 \%$ for tumors $\geq 4 \mathrm{~mm}$ thick. Multivariate analysis indicated that tumor thickness was the only independent predictor of neck failure $(P=0.02)$.

Traditional tumor-nodes-metastases (TNM) staging does not incorporate the third dimension, i.e., the tumor thickness. Thus, pTNM may understage the disease, especially in infiltrative tumors.

Although thickness is an independent risk factor for regional recurrence, there has been no consensus on the benefit of adjuvant RT in management of early oral tongue cancer with increased thickness. No prospective randomized trial has ever been conducted addressing this issue.

Our institutional practice is to radiate tumors which are $\geq 1 \mathrm{~cm}$ in thickness even in the absence of other adverse prognostic factors.

\section{Perineural Invasion}

PNI is defined as tumor invasion of the perineural sheath or epineurium. A study by Brown et al. ${ }^{[20]}$ demonstrated that the presence of PNI decreased the 2-year survival from $82 \%$ to $52 \%$. Lydiatt et al. ${ }^{[24]}$ in a study of 156 patients with stage I and II tongue cancer found that local control rate at 5 years was $38 \%$ in patients with PNI versus $78 \%$ in patients without PNI. Thiagarajan S et al. ${ }^{[22]}$ found PNI to significantly affect DFS. Thus, extensive PNI is a clear indication of adjuvant RT.

Despite the clear importance of PNI, the percentage of mucosal SCC positive for PNI varies in literature from $5 \%{ }^{[24]}$ to $52 \%{ }^{[25]}$ This discrepancy results from identifying PNI only in large diameter nerves. However, the presence of PNI in small unnamed nerves may not be clinically apparent; but the association between PNI and prognosis is independent of the nerve diameter. ${ }^{[25]}$ Thus, the pathologist must look for PNI along unnamed nerves also while microscopically examining the histopathological specimen.

Confusion arises in patients with focal PNI without any other adverse tumor factor, whether to give adjuvant RT or not. Although there are no clear cut guidelines, the NCCN treatment guidelines for head and neck cancer considers PNI as an adverse factor and most oncologists recommend adjuvant RT in patients having PNI. In a recent study assessing the role of adjuvant radiotherapy in early tongue cancers with minor risk factors (MAFS), PNI was found to have a significant impact on disease free survival (DFS). Patients with MAFS receiving adjuvant RT had improved DFS as compared to those undergoing surgery alone. ${ }^{[26]}$

\section{Vascular Invasion}

Vascular invasion is defined as the presence of neoplastic epithelium in the endothelial lined vascular channels. Larsen et al. ${ }^{[27]}$ in a study of 144 patients of head and neck carcinoma found vascular invasion to be present in $>50 \%$ of pathological specimens. These patients had significantly more chances of harboring concomitant neck nodal metastasis and had increased incidence of distant metastasis. In another study by Close et al., ${ }^{[28]}$ the presence of vascular invasion corelated with increased risk of subsequent locoregional recurrence. Microscopically, vascular involvement is typically seen at the invasive front of the tumor and a perivascular lymphocytic infiltrate, including lymphoid aggregates, should raise the possibility of vessel involvement.

The presence of vascular invasion is an indication of adjuvant RT.

\section{Histological Grading System}

Although not routinely reported and not incorporated in the TNM staging system, histological grading system provides immense information in treatment planning. Initially proposed by Broders ${ }^{[29]}$ and subsequently modified by Jakobsson et al. ${ }^{[30]}$ and Anneroth et al. ${ }^{[31]}$ this grading system incorporates five histological parameters - degree of keratinization, nuclear polymorphism, number of mitosis (high-power field), pattern of tumor, and lymphoplasmacytic invasion. Bryne et al. ${ }^{[32]}$ applied this grading system to the most anaplastic fields in the most invasive parts of the tumor and named it invasive cell grading system (ICG) [Table 2]. ${ }^{[32]}$ 


\begin{tabular}{|c|c|c|c|c|}
\hline $\begin{array}{l}\text { Morphological } \\
\text { features }\end{array}$ & 1 & 2 & 3 & 4 \\
\hline $\begin{array}{l}\text { Degree of } \\
\text { Keratinization }\end{array}$ & $\begin{array}{l}\text { Highly Keratinized } \\
(>50 \% \text { of cells) }\end{array}$ & $\begin{array}{l}\text { Moderately Keratinized } \\
(5-20 \% \text { of cells) }\end{array}$ & $\begin{array}{l}\text { minimal Keratinization }(5-20 \% \\
\text { of cells) }\end{array}$ & $\begin{array}{l}\text { No Keratinization } \\
(0-5 \%)\end{array}$ \\
\hline $\begin{array}{l}\text { Nuclear } \\
\text { polymorphism }\end{array}$ & $\begin{array}{l}\text { Little nuclear } \\
\text { polymorphism } \\
(>75 \% \text { mature cells) }\end{array}$ & $\begin{array}{l}\text { Moderately abundant } \\
\text { nuclear polymorphism } \\
(50-75 \% \text { mature cells })\end{array}$ & $\begin{array}{l}\text { Abundant nuclear polymorphism } \\
\text { (25-50\% mature cells) }\end{array}$ & $\begin{array}{l}\text { Extreme nuclear } \\
\text { polymorphism } \\
(0-25 \% \text { mature cells })\end{array}$ \\
\hline $\begin{array}{l}\text { Number of mitosis } \\
\text { (high power field) }\end{array}$ & $0-1$ & $2-3$ & $4-5$ & $>5$ \\
\hline Patterns of invasion & $\begin{array}{l}\text { Pushing, well } \\
\text { delineated infiltrating } \\
\text { borders }\end{array}$ & $\begin{array}{l}\text { infiltrating, solid cords, } \\
\text { bands or strands }\end{array}$ & $\begin{array}{l}\text { Small groups or cords of } \\
\text { infiltrating cells }(n>15)\end{array}$ & $\begin{array}{l}\text { Marked and } \\
\text { widespread cellular } \\
\text { dissociation in } \\
\text { small group of cells } \\
(n<15) \text { and or in } \\
\text { single cells }\end{array}$ \\
\hline $\begin{array}{l}\text { Host response } \\
\text { (lympho-plasmacytic } \\
\text { infiltrate) }\end{array}$ & Marked & Moderate & Slight & None \\
\hline
\end{tabular}

Bryne et al. in two cohorts of 68 and 61 patients with oral cavity SCC showed that ICG was an independent and significant risk factor for survival. Patients with a score between 5 and 10 experienced a $57 \%$ survival as compared to $19 \%$ in patients with a score $>10 . .^{[32,33]}$

Spiro et al. ${ }^{[34]}$ retrospectively assessed the pattern of invasion in 150 patients of oral tongue and found that an endophytic growth pattern were associated with a significant increase in local recurrence $(P<0.04)$. With higher grades of infiltration (Grade 3 or 4 ), the tumors tended to be larger and the patients younger. Although the likelihood of nodal involvement and subsequent distant metastasis was significantly greater in those with Grade 3 or Grade 4 patterns $(P<0.0003$ and $<0.01$, respectively), there was no impact on local recurrence. Cumulative survival was significantly reduced when the pattern of tumor invasion was of higher grade $(P<0.01)$.

In addition to growth pattern, lymphoplasmacytic infiltration also has prognostic significance. It denotes the host immugenic response against the tumor. Anneroth et al. found that the presence of intra- and peri-tumoral infiltration decreased the chances of cervical lymph node metastasis. $^{[32]}$

The commonly used NCCN guidelines do not include poor tumor differentiation as an adverse risk factor requiring adjuvant treatment. ${ }^{[15]}$ Although there is no robust evidence, we prefer treating poorly differentiated SCC with adjuvant radiation even in the absence of other adverse factors.

\section{Nonvalidated Parameters}

These parameters widely range from simple cost-effective to costly and time-consuming ones. Not routinely reported, these can at times be of immense importance in planning adjuvant treatment.

\section{DNA Ploidy}

DNA nondiploid tumors behave more aggressively as compared to DNA diploid tumors. Byers et al. ${ }^{[35]}$ in a series of ninety-one patients of oral tongue cancer found that DNA aneuploidy was an independent predictor for nodal metastasis. Hemmer et al. ${ }^{[36]}$ in a series of 47 patients found DNA aneuploidy significantly increased tumor size and poorer grade of differentiation as compared to the DNA diploid tumors.

The role DNA diploidy needs to be evaluated in tongue cancers and this simple time and cost-effective parameter can easily be included in routine histopathology reports.

\section{Ki 67 Index}

$\mathrm{Ki} 67$ is a nuclear protein and is a cellular marker of proliferation. Its role has been well validated in carcinomas of the prostrate, brain, breast, and nephroblastoma. In a study by Valente et al., ${ }^{[37]} \mathrm{Ki} 67$ immunostaining was used to predict the response to RT in oral SCC. Thirty-one cases of SCC were stained at diagnosis and after $10 \mathrm{~Gy}$ of RT. The percentage difference of Ki67 positive cells among the biopsy specimens taken at the beginning and after 10 Gy was correlated with the clinical response obtained at the end of the treatment and its significance determined. The percentage of Ki67 positive cells at diagnosis had no significant correlation with the final therapeutic outcome. By contrast, a decrease in the growth fraction after 10 Gy of RT was significantly correlated with the complete response $(P<0.01)$. Thus, the authors concluded that $\mathrm{Ki} 67$ index can be a good prognostic marker after the first week of RT to separate the good versus poor outcome patients. A high Ki67 index denotes poor tumor biology and further research needs to focus on the role of adjuvant radiation in tumors with high Ki67 index. 


\section{Vascular Density}

Vascular density is the determination of the number of microvessels in tissue and is of importance in cancer owing to angiogenesis and lymphatic spread. Tongue squamous carcinoma is notorious for lymphatic spread. Lymphatic vascular density (LVD) measurement is a marker of regional spread and thus aggressiveness. It is measured using immunohistochemistry. Yan et al. ${ }^{[38]}$ compared the LVD in normal tongue and SCC tongue tissue and found that LVD was higher in malignant tongue tissue. OS was significantly shorter in patients with high LVD. The measurement of vascular density and its relation with RT is still at the preliminary level. Chen et al. ${ }^{[39]}$ reported that single or fractioned doses of radiation decreases the vascular density in adenocarcinoma of mouse prostrate. However, routine reporting of this parameter may help us understand better the role of RT on vascular density and prognostic significance of the latter.

\section{Molecular Markers}

Transformation of a normal cell to a malignant cell is a result of multiple molecular events occurring at the level of protooncogenes and tumor suppressor genes. Each molecular event carries its own prognostic and therapeutic implications. These are being extensively studied and are the basis of novel targeted therapies.

p53, the guardian of the genome, is a vital constituent of the G1S checkpoint and an inducer of apoptosis in cells undergoing genotypic damage. Loss of this tumor suppressor gene, mostly by homozygous deletion, occurs in $>60 \%$ of head and neck cancers. Hegde et al. ${ }^{[40]}$ found that mutations in the p53 gene were associated with unfavorable overall and DFS in a group of 39 patients with head and neck cancer. Furthermore, the response to therapy was poorer in the mutated group of patients.

Atula et al..$^{[4]}$ studied p53 mutations in tongue cancer and found mutations in $54 \%$ of the samples. The mutations correlated with tumor size and grading. Other studies have demonstrated that $\mathrm{p} 53$ mutation precedes and favors the appearance of metastasis. ${ }^{[42,43]}$ Thus, p53 mutation is associated with aggressive nature of tongue cancers and in general head and neck cancers.

Although human papilloma virus (HPV) 16 and 18 has emerged as one of the major carcinogens in head and neck squamous cell cancers, its role in oral tongue cancer seems somewhat overrated. HPV is a major carcinogen for base of tongue SCC. Most studies assessing HPV DNA or p16 assay for tongue lesions have not separately categorized oral tongue from base tongue lesions. Kantola et al. ${ }^{[44]}$ found that none of 105 mobile tongue cancer patients harbored HPV. Two other studies by Dahlgren et al. ${ }^{[45]}$ and Liang et $a l .{ }^{[46]}$ have reported HPV frequencies in oral tongue cancer of $2.3 \%$ and $1.96 \%$, respectively, thus confirming its small etiopathogenetic role, at least in the mobile portion of the tongue cancers as compared to HPV-negative tumors. ${ }^{[45]}$
HPV positive tumors are prognostically better as compared to HPV-negative tumors.

Epidermal growth factor receptor (EGFR) is a $170-\mathrm{kDa}$ transmembrane glycoprotein located on chromosome $7 \mathrm{p} 12$. Its main ligands epidermal growth factor (EGF) and transforming growth factor alpha (TGF- $\alpha$ ), bind to the extracellular domain of EGFR and thus lead to the downstream activation of ras oncoprotein, which ultimately leads to cell cycle progression, decreased apoptosis, increased angiogenesis, and thus metastatic potential. EGFR and its ligand TGF- $\alpha$ are overexpressed in $>90 \%$ of head and neck cancers. Data regarding the expression and prognostic value of EGFR in tongue cancer are limited. However, its overexpression is typically associated with greater radio- and chemoresistance and shorter DFS and OS. The development of monoclonal antibodies (MABs) against EGFR has been a milestone achievement in treating these cancers with otherwise dismal prognosis. Cetuximab, the prototype drug, has been shown to improve locoregional control, progression-free survival and OS when combined with RT as compared to radical RT in advanced head and neck cancers in a phase III randomized control trial. ${ }^{[46]}$ Elderly patients who cannot tolerate chemotherapy and those with medical illness not fit for chemotherapy can be treated with this novel drug.

Vascular endothelial growth factor (VEGF) is a family of proteins with specific angiogenic potential. There are limited data concerning the role of VEGF overexpression and tongue cancer. Kim et al. ${ }^{[48]}$ studied the expression of VEGF in 38 oral tongue cancer patients and found a significant correlation between VEGF expression and the extent of tumor invasion $(P=0.002)$. Furthermore, the tumor-free survival of the VEGF-positive patients was significantly worse than that of the VEGF-negative patients $(P=0.019)$.

\section{Next Generation Sequencing}

Head and neck cancers are predominantly an environmental disease caused by tobacco, alchohol, and HPV. However, many patients, especially of tongue cancers, are young without any habits. This group of patients' harbor-aggressive disease which is clinically and histopathologically a distinct entity highlighting the role of genetic factors in carcinogenesis. ${ }^{[49]}$

NGS accelerates the process of studying DNA by generating digital and quantifiable data that can be mapped back to the genome. Findings from next generation sequencing (NGS) studies of head neck squamous cancer will help us better understand the genetic aspects of a tumor traditionally considered environmental. This may open up a completely new avenue of approach and treatment based on targeted therapy.

Assessment of molecular markers and NSG are costly and time-consuming. Their role is limited in routine histopathological analysis. However, they can de used in 
atypical scenarios such as young patients, no addiction, multiple primaries, and thus help develop targeted therapies based on the genetic mutation.

The role of molecular markers is further highlighted in treatment of patients with recurrent cancers where immunotherapy possibly holds a promising role. As compared to non selective cytotoxic chemotherapeutic agents, immunotherapy has more specific targeted action thus reducing the non desirable cytotoxic effects commonly occurring with conventional chemotherapeutic agents. Molecular marker analysis like EGFR, PD-1, PD-L1 can help choose patients suitable for a specific targeted therapy as well as monitor the treatment response.

The most commonly used targeted agents in cancer treatment are monoclonal antibodies (MAB). Cetuximab is the only MAB approved for treatment of head neck SCC. It blocks EGF signals by targeting EGF receptors on the tumor cells. Additionally it helps in immune surveillance by activating antibody dependant cytotoxic activity (ADCC) resulting in cancer cell death. ${ }^{[50]} \mathrm{A}$ randomized phase III study demonstrated a significant benefit in OS and progression free survival of adding cetuximab to conventional palliative chemotherapy in recurrent or metastatic head and neck SCC. ${ }^{[51]}$

A humanized IgG4 PD-1-blocking MAB, pembrolizumab has been granted FDA approval for the treatment of melanoma. Its role is now being evaluated in head and neck cancers in various clinical trials including two phase III trials- Keynote 040 and 048. PD-L1 blocking MABs durvalumab, atezolizumab and avelumab are under investigation for head and neck SCC in trial settings.

In recurrent and metastatic head and neck setting post surgery and CCRT the EXTREME trial showed benefit of addition of Cetuximab in healthy individuals, recent phase III CheckMate 141 trial has shown significant longer over all survival with Nivolumab, an anti-programmed death 1 (PD-1) monoclonal antibody. ${ }^{[52]}$ Although it has been approved by the US FDA presently it has high cost of treatment which recurrent two weekly.

\section{Conclusion}

Through this review, we have tried to highlight the importance of histopathology in the management of patients with early tongue cancer. In our opinion, histopathology in addition to routine parameters should also include some simple and cost-effective factors whose importance in clinical practice is underrated due to the lack of available data. We strongly propose the need for a large prospective trial looking into the prognostic significance of various validated and nonvalidated histopathological factors in early tongue cancers. This can redefine the importance of the commonly used parameters and also bring to light the significance of certain other factors which till date have not received adequate attention. Based on the significance of each parameter, a normogram needs to be formulated which will help establish a uniform guideline for the role of adjuvant treatment in early tongue cancers. This may at least to some extent improve the survival of this common but deceptive and aggressive disease.

\section{Financial support and sponsorship}

Nil.

\section{Conflicts of interest}

There are no conflicts of interest.

\section{References}

1. Prince S, Bailey BM. Squamous carcinoma of the tongue: Review. Br J Oral Maxillofac Surg 1999;37:164-74. Available from: https://www.google.co.in/search?q=Prince + S\% $2 \mathrm{C}+$ Bailey + BM. + Squamous + carcinoma + of + the + tongue $\% 3 \mathrm{~A}+$ Review. $+\mathrm{Br}+$ $\mathrm{J}+$ Oral+Maxillofac+Surg+1999\%3B37\%3A164\%E2\%80\%9174. $\& \mathrm{rlz}=1 \mathrm{C} 1 \mathrm{LENP}$ _enUS715US715\&oq $=$ Prince $+\mathrm{S} \% 2 \mathrm{C}+\mathrm{Bailey}+\mathrm{B}$ M.+Squamous + carcinoma + of + the + tongue $\% 3 \mathrm{~A}+$ Review. $+\mathrm{Br}+\mathrm{J}+$ Oral+Maxillofac+Surg+1999\%3B37\%3A164\%E2\%80\%9174.\&a $\mathrm{qs}=$ chrome..69i57.1574j0j4\&sourceid=chrome\&ie=UTF-8. [Last cited on 2017 Nov 29].

2. Shemen LJ, Klotz J, Schottenfeld D, Strong EW. Increase of tongue cancer in young men. JAMA 1984 12;252:1857.

3. Depue RH. Rising mortality from cancer of the tongue in young white males. N Engl J Med 1986;315:647.

4. Davis S, Severson RK. Increasing incidence of cancer of the tongue in the United States among young adults. Lancet Lond Engl 1987;2:910-1.

5. Rusthoven K, Ballonoff A, Raben D, Chen C. Poor prognosis in patients with stage I and II oral tongue squamous cell carcinoma. Cancer 2008;112:345-51.

6. Han JM, Wu GH, Zeng ZY, Chen FJ, Chen WK, Li H, et al. Postoperative recurrence-related factors of 125 patients with cT1-2N0 squamous cell carcinoma of the oral tongue. Ai Zheng Aizheng Chin J Cancer 2007;26:661-5.

7. An SY, Jung EJ, Lee M, Kwon TK, Sung MW, Jeon YK, et al. Factors related to regional recurrence in early stage squamous cell carcinoma of the oral tongue. Clin Exp Otorhinolaryngol. 2008;1:166-70.

8. Sopka DM, Li T, Lango MN, Mehra R, Liu JC-J, Burtness B, et al. Dysplasia at the margin? Investigating the case for subsequent therapy in "low-risk" squamous cell carcinoma of the oral tongue. Oral Oncol 2013;49:1083-7.

9. Mantsopoulos K, Psychogios G, Künzel J, Waldfahrer F, Zenk J, Iro H. Primary surgical therapy for locally limited oral tongue cancer. BioMed Res Int 2014;2014:738716.

10. Yanamoto S, Yamada S, Takahashi H, Kawasaki G, Ikeda H, Shiraishi T, et al. Predictors of locoregional recurrence in T12N0 tongue cancer patients. Pathol Oncol Res POR 2013;19:795803.

11. Chen TY, Emrich LJ, Driscoll DL. The clinical significance of pathological findings in surgically resected margins of the primary tumor in head and neck carcinoma. Int J Radiat Oncol Biol Phys 1987;13:833-7.

12. Loree TR, Strong EW. Significance of positive margins in oral cavity squamous carcinoma. Am J Surg 1990;160:410-4.

13. Woolgar JA, Triantafyllou A. A histopathological appraisal of surgical margins in oral and oropharyngeal cancer resection specimens. Oral Oncol 2005;41:1034-43.

14. Bernier J, Cooper JS, Pajak TF, van Glabbeke M, Bourhis 
J, Forastiere A, et al. Defining risk levels in locally advanced head and neck cancers: a comparative analysis of concurrent postoperative radiation plus chemotherapy trials of the EORTC (\#22931) and RTOG (\# 9501). Head Neck 2005;27:843-50.

15. Head-and-neck.pdf [Internet]. Available from: https://www.nccn. org/professionals/physician_gls/pdf/head-and-neck.pdf. [Last cited on 2017 Nov 29].

16. Grégoire V, Lefebvre JL, Licitra L, Felip E, EHNS-ESMOESTRO Guidelines Working Group. Squamous cell carcinoma of the head and neck: EHNS-ESMO-ESTRO Clinical Practice Guidelines for diagnosis, treatment and follow-up. Ann Oncol Off J Eur Soc Med Oncol 2010;21 Suppl 5:v184-6.

17. Yuen AP, Lam KY, Wei WI, Lam KY, Ho CM, Chow TL, et al. A comparison of the prognostic significance of tumor diameter, length, width, thickness, area, volume, and clinicopathological features of oral tongue carcinoma. Am J Surg 2000;180:139-43.

18. Woolgar JA. Carcinoma of the tongue: pathological considerations in management of the neck. J R Soc Med 1996;89:611-5.

19. Fukano H, Matsuura H, Hasegawa Y, Nakamura S. Depth of invasion as a predictive factor for cervical lymph node metastasis in tongue carcinoma. Head Neck 1997;19:205-10.

20. Brown B, Barnes L, Mazariegos J, Taylor F, Johnson J, Wagner RL. Prognostic factors in mobile tongue and floor of mouth carcinoma. Cancer 1989;64:1195-202.

21. Fakih AR, Rao RS, Borges AM, Patel AR. Elective versus therapeutic neck dissection in early carcinoma of the oral tongue. Am J Surg 1989;158:309-13.

22. Thiagarajan S, Nair S, Nair D, Chaturvedi P, Kane SV, Agarwal JP, et al. Predictors of prognosis for squamous cell carcinoma of oral tongue. J Surg Oncol 2014;109:639-44.

23. Ganly I, Goldstein D, Carlson DL, Patel SG, O'Sullivan B, Lee $\mathrm{N}$, et al. Long-term regional control and survival in patients with "low-risk," early stage oral tongue cancer managed by partial glossectomy and neck dissection without postoperative radiation: the importance of tumor thickness. Cancer 2013;119:1168-76.

24. Lydiatt DD, Robbins KT, Byers RM, Wolf PF. Treatment of stage I and II oral tongue cancer. Head Neck 1993;15:308-12.

25. Fagan JJ, Collins B, Barnes L, D'Amico F, Myers EN, Johnson JT. Perineural invasion in squamous cell carcinoma of the head and neck. Arch Otolaryngol Head Neck Surg 1998; 124:637-40.

26. Katz O, Nachalon $Y$, Hilly $O$, Shpitzer $T$, Bachar G, Limon $\mathrm{D}$, et al. Radiotherapy in early-stage tongue squamous cell carcinoma with minor adverse features. Head Neck 2017;39:147-50.

27. Larsen SR, Johansen J, Sørensen JA, Krogdahl A. The prognostic significance of histological features in oral squamous cell carcinoma. J Oral Pathol Med Off Publ Int Assoc Oral Pathol Am Acad Oral Pathol 2009;38:657-62.

28. Close LG, Brown PM, Vuitch MF, Reisch J, Schaefer SD. Microvascular invasion and survival in cancer of the oral cavity and oropharynx. Arch Otolaryngol Head Neck Surg 1989;115:1304-9.

29. Broders AC. Squamous cell epithelioma of the lip. JAMA 1920;74:656-64. Available from: https://www.google.co.in/ search?rlz=1C1LENP_enUS715US715\&ei=ud4eWuD6NcnWv gTtzJ-YBw\&q=Broders + AC. + Squamous + cell + epithelioma + of the+lip. + JAMA $+1920 \% 3$ B 74\%3 A656\%E2\%80\%9164\&oq=B roders + AC. + Squamous + cell + epithelioma + of + the+lip. + JAMA $+1920 \% 3 \mathrm{~B} 74 \% 3 \mathrm{~A} 656 \% \mathrm{E} 2 \% 80 \% 9164 \& \mathrm{gs} \_1=$ psy-ab.3...10924 $.11426 .0 .12310 .2 .2 .0 .0 .0 .0 .241 .383 .0 \mathrm{j} 1 \mathrm{j} 1.2 .0 \ldots . . .01 \mathrm{c} .1 .64 . \mathrm{psy}-$ ab..0.0.0...0.kTxJWhoOPRA. [Last cited on 2017 Nov 29].
30. Jakobsson PA, Eneroth CM, Killander D, Moberger G, Mårtensson $\mathrm{B}$. Histologic classification and grading of malignancy in carcinoma of the larynx. Acta Radiol Ther Phys Biol 1973;12:1-8.

31. Anneroth G, Batsakis J, Luna M. Review of the literature and a recommended system of malignancy grading in oral squamous cell carcinomas. Scand J Dent Res 1987;95:229-49.

32. Bryne M, Koppang HS, Lilleng R, Stene T, Bang G, Dabelsteen E. New malignancy grading is a better prognostic indicator than Broders' grading in oral squamous cell carcinomas. J Oral Pathol Med Off Publ Int Assoc Oral Pathol Am Acad Oral Pathol 1989;18:432-7.

33. Bryne M, Koppang HS, Lilleng R, Kjaerheim A. Malignancy grading of the deep invasive margins of oral squamous cell carcinomas has high prognostic value. J Pathol 1992;166:375-81.

34. Spiro RH, Guillamondegui O, Paulino AF, Huvos AG. Pattern of invasion and margin assessment in patients with oral tongue cancer. Head Neck 1999;21:408-13.

35. Byers RM, El-Naggar AK, Lee YY, Rao B, Fornage B, Terry $\mathrm{NH}$, et al. Can we detect or predict the presence of occult nodal metastases in patients with squamous carcinoma of the oral tongue? Head Neck 1998;20:138-44.

36. Hemmer J, Schön E, Kreidler J, Haase S. Prognostic implications of DNA ploidy in squamous cell carcinomas of the tongue assessed by flow cytometry. J Cancer Res Clin Oncol 1990;116:83-6.

37. Valente G, Orecchia R, Gandolfo S, Arnaudo M, Ragona R, Kerim S, et al. Can Ki67 immunostaining predict response to radiotherapy in oral squamous cell carcinoma? J Clin Pathol 1994;47:109-12.

38. Yan J, Jiang Y, Ye M, Liu W, Feng L. The clinical value of lymphatic vessel density, intercellular adhesion molecule 1 and vascular cell adhesion molecule 1 expression in patients with oral tongue squamous cell carcinoma. J Can Res Ther 2014;10:125-30.

39. Chen FH, Chiang CS, Wang CC, Tsai CS, Jung SM, Lee CC, et al. Radiotherapy decreases vascular density and causes hypoxia with macrophage aggregation in TRAMP-C1 prostate tumors. Clin Cancer Res Off J Am Assoc Cancer Res 2009;15:1721-9.

40. Hegde PU, Brenski AC, Caldarelli DD, Hutchinson J, Panje WR, Wood NB, et al. Tumor angiogenesis and p53 mutations: prognosis in head and neck cancer. Arch Otolaryngol Head Neck Surg 1998;124:80-5.

41. Atula S, Kurvinen K, Grénman R, Syrjänen S. SSCP pattern indicative for $\mathrm{p} 53$ mutation is related to advanced stage and high-grade of tongue cancer. Eur J Cancer B Oral Oncol 1996;32:222-9.

42. Sameshima Y, Matsuno Y, Hirohashi S, Shimosato Y, Mizoguchi $\mathrm{H}$, Sugimura $\mathrm{T}$, et al. Alterations of the p53 gene are common and critical events for the maintenance of malignant phenotypes in small-cell lung carcinoma. Oncogene 1992;7:451-7.

43. Pohl J, Goldfinger N, Radler-Pohl A, Rotter V, Schirrmacher V. p53 increases experimental metastatic capacity of murine carcinoma cells. Mol Cell Biol 1988;8:2078-81.

44. Kantola S, Parikka M, Jokinen K, Hyrynkangs K, Soini Y, Alho OP, et al. Prognostic factors in tongue cancer - relative importance of demographic, clinical and histopathological factors. Br J Cancer 2000;83:614-9.

45. Dahlgren L, Dahlstrand HM, Lindquist D, Högmo A, Björnestål L, Lindholm J, et al. Human papillomavirus is more common in base of tongue than in mobile tongue cancer and is a favorable prognostic factor in base of tongue cancer patients. Int J Cancer 2004;112:1015-9.

46. Liang K, Ang KK, Milas L, Hunter N, Fan Z. The epidermal 
growth factor receptor mediates radioresistance. Int $\mathrm{J}$ Radiat Oncol Biol Phys 2003;57:246-54.

47. Bonner JA, Harari PM, Giralt J, Azarnia N, Shin DM, Cohen RB, et al. Radiotherapy plus cetuximab for squamous-cell carcinoma of the head and neck. N Engl J Med 2006;354:567-78.

48. Kim SH, Cho NH, Kim K, Lee JS, Koo BS, Kim JH, et al. Correlations of oral tongue cancer invasion with matrix metalloproteinases (MMPs) and vascular endothelial growth factor (VEGF) expression. J Surg Oncol 2006;93:330-7.

49. Sharma P, Shah SV, Taneja C, Patel AM, Patel MD. A prospective study of prognostic factors for recurrence in early oral tongue cancer. J Clin Diagn Res JCDR 2013;7:2559-62.
50. Srivastava RM, Lee SC, Andrade Filho PA, Lord CA, Jie HB, Davidson $\mathrm{HC}$, et al. Cetuximab-activated natural killer and dendritic cells collaborate to trigger tumor antigen-specific T-cell immunity in head and neck cancer patients. Clin Cancer Res Off J Am Assoc Cancer Res 2013;19:1858-72.

51. Vermorken JB, Mesia R, Rivera F, Remenar E, Kawecki A, Rottey $\mathrm{S}$, et al. Platinum-based chemotherapy plus cetuximab in head and neck cancer. N Engl J Med 2008;359:1116-27.

52. Ferris RL, Blumenschein G, Fayette J, Guigay J, Colevas $\mathrm{AD}$, Licitra $\mathrm{L}$, et al. Nivolumab for Recurrent Squamous-Cell Carcinoma of the Head and Neck. N Engl J Med 2016;375:1856-67. 